\title{
MASHLAHAH AL MURSALAH DALAM KONSEP KENEGARAAN MENURUT IMAM AL GHAZALI
}

\author{
Siti Haniatunnisa ${ }^{\varpi}$ \\ Sekolah Tinggi Ilmu Fikih (STIF) Syeikh Nawawi Tanara Serang Banten - Indonesia
}

\begin{abstract}
Abstrak
Imam al Ghazali sebagai Cendekiawan Islam yang ahli di bidang ushul fiqh, pemikirannya di bidang ushul menjadi rujukan di seluruh dunia dan juga di Indonesia selama berabad-abad. Ia juga salah satu ulama yang menggunakan pendekatan Mashlahah al-mursalah hasil ijtihad. Ia merumuskan metodologi dalam buku-bukunya yang terkenal antara lain Al-Mustashfa, Syifa'ul Ghalil dan al-Mankhul tentang ketentuan penggunaan mashlahah al mursalah. Selain itu al Ghazali juga merumuskan konsep negara. Konsep negara yang dirumuskan oleh al Ghazali berdiri atas dasar teori interdependensi dan teori teo-demokrasi. Dalam konsep kenegaraan, kita menemukan bahwa al Ghazali menggunakan prinsip mashlahah sebagai dasar atau acuan dalam membangun negara. Al Ghazali dalam konsep teo-demokrasi menggunakan Mashlahah al Mursalah sebagai dasar hukum dalam rangka membangun negara berdaulat rakyat dengan menggunakan prinsip ketuhanan (Mabadi Rabbaniyah). Konsep teo-demokrasi, merupakan konsep negara moderat (tawashutiyyan), yang tidak berbentuk Negara Ketuhanan (teokrasi) atau negara Sekuler, tetapi berada di tengah-tengah antara dua model Negara tersebut, yaitu negara Negara yang tetap dalam koridor tata krama dan prinsip ketuhanan sekaligus memberikan kedaulatan dalam kehidupan teknis suatu negara kepada suatu bangsa.
\end{abstract}

Kata Kunci: Imam al-Ghazali, cendekiawan islam, ushul fiqh 


\begin{abstract}
Imam al Ghazali as Islamic Scholar expert in the field of ushul fiqh, His thoughts in the field of ushul serve as a reference throughout the world and also in Indonesia for centuries. He is also one of the scholar who uses Mashlahah al-mursalah approach results in ijtihad. He formulates in the methodology in his famous books include Al-Mustashfa, Syifa'ul Ghalil and al-Mankhul on the provisions of the use mashlahah al mursalah. In addition al Ghazali also formulated a concept of state. The concept of state formulated by al Ghazali stands on the basis of the theory of interdependency and the theory of theo-democracy. In the concept of statehood, we find that al Ghazali uses the principle of Mashlahah as the basis or reference in the built of state. Al Ghazali in the concept of theo-democracy using Mashlahah al Mursalah as the basis of law in order to build people's sovereign State by using the principles of divinity (Mabadi Rabbaniyah). The concept of theo-democracy, is a concept of a moderate state (tawashutiyyan), which is not in the form of God State (theocracy) or Secular state, but it is in the middle between that two models of the State, namely the State which remain within the corridor etiquette and principles of divinity yet at the same time provide a soverignity in technical life of a country to a nation.
\end{abstract}

Keywords: Imam al-Ghazali,Islamic scholar, ushul figh

Copyright (c) 2021 Siti Haniatunnisa.

$\square$ Corresponding author : Siti Haniatunnisa

Email Address : haniatunnisa13@yahoo.com

\title{
PENDAHULUAN
}

Permasalahan kenegaraan (dusturiyyah) merupakan bagian dari ruang lingkup muamalah, negara merupakan asas dari terciptanya hubungan manusia (muamalah) yang damai dan sejahtera. Tidak ada dalil di dalam al Qur'an atau hadits yang menyatakan secara detail mengenai negara. Dalil di dalam al Qur'an atau hadits hanya memuat mengenai prinsip-prinsip dalam bernegara. Namun, permasalahan kenegaraan merupakan hal yang penting, karena negara merupakan sarana dalam mencapai kebahagiaan dunia dan akhirat.

Namun untuk memastikan bahwa konsep bernegara itu tidak keluar dari pada syariah maka diperlukan adanya suatu pendekatan hukum Islam dalam menentukan permasalahan-permasalahan kenegaraan.

Mashlahah al-mursalah dinilai sebagai pendekatan yang paling sesuai dalam menentukan hukum tersebut. Sebagaimana pendekatan ini sangat berkesuaian dalam karakter negara yang bersifat dinamis, dikatakan bahwa agama Islam merupakan agama yang (دين الإسلام دين ألإصلاح) dan bahwa risalah Islami merupakan risalah kebaikan dan negara merupakan sarana yang paling penting bagi manusia sebagai makhluk sosial dalam mencapai kebaikan di dunia maupun akhirat.

Imam al Ghazali sebagai 'ulama yang mumpuni dalam bidang ushul, pemikiranpemikiran dalam bidang $u$ shul figh hanya dijadikan sebagai acuan di seluruh dunia dan juga di Indonesia. Beliau juga salah satu 'ulama yang banyak menggunakan pendekatan mashlahah al-mursalah dalam hasil ijtihadnya. Beliau merumuskan di dalam kitab-kitab yang terkenal diantaranya Mustashfa, Syifa'ul Ghalil dan al-Mankhul mengenai ketentuan dalam menggunakan mashlahah al mursalah.

Selain ahli bidang ushul figh, al Ghazali juga merumuskan suatu konsep kenegaraan. Konsep kenegaraan yang dirumuskan oleh al Ghazali berdiri atas dasar teori interdependensi dan berbentuk teodemokrasi.

Dalam konsep kenegaraan tersebut, kami menemukan bahwasanya al Ghazali menggunakan prinsip kemashlahatan sebagai dasar atau acuan di dalam bernegara. 
Oleh karenanya, penelitian ini bermaksud mencari keterkaitan dan penerapan metode ushul figh mashlahah al mursalah sebagai dasar hukum di dalam konsep bernegara menurut pandangan Imam al Ghazali. Selain itu akan membandingkn dengan bentuk negara teokrasi dan demokrasi sekuler yang berbeda dari bentuk negara yang dirumuskan oleh al Ghazali.

\section{METODOLOGI}

Metode penelitian yang digunakan oleh penulis adalah jenis penelitian kualitatif melalui library research (kajian studi kepustakaan), dengan cara mengumpulkan data atau bahan-bahan seperti buku-buku, jurnal, kitab, dan al-Qur'an dan Hadits yang berkaitan dengan tema pembahasan dan permasalahannya, yang diambil dari sumber-sumber kepustakaan, kemudian dianalisis.

\section{ANALISIS DAN PEMBAHASAN Mashlahah Al Mursalah}

Dalam hukum Islam segala sesuatu haruslah bersandarkan pada al Qur'an dan hadits, namun apabila permasalahan-permasalahan tersebut tidak terdapat di dalam al Qur' an hadits maka kemashlahatan dapat digunakan sebagai dalil. Dikatakan dalam kaidah

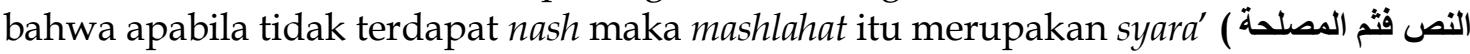
). Al-ghazali di dalam bukunya Al-mustashfa membagi mashalahah menjadi 3 (tiga) yaitu : Maslahah al Mu'atabarah"1, Mashlahah al Mulghah dan Mashlahah al Mursalah. Mashlahah al mursalah menurut al Ghazali ialah mashlahat yang sejalan dengan tindakan syara' (mula 'imah li-tasarrufat asy-syar'), yang dimaksudkan untuk memelihara tujuan syara' (hukum Islam), tidak ada dalil tertentu yang menunjukannya dan kemashlahatan itu tidak berlawanan dengan al Qur'an, sunnah atau ijma'.

Mashlahah itu relevan dan seirama dengan tindakan syara' (penetapan hukum Islam) yang tiada lain dimaksudkan untuk memelihara agama, jiwa, akal, harta benda, dan kehormatan/ keturunan. Inilah dinamakan oleh al Ghazali sebagai mabadiu al khamsah.

Ukuran dalam mashlahat al mursalah adalah terpeliharanya mabaidiu al khamsah (terpeliharanya agama, jiwa, akal, keturunan dan harta). Terpeliharanya mabadiul al khamsah tersebut merupakan patokan dari wujudnya kemaslahatan.

Penggunaan mashlahah al mursalah dalam kenegaraan dapat dilihat dari beberapa ijtihad yang dilakukan oleh Umar bin Khattab dalam menata administrasi pemerintahan yaitu: mendirikan perkantoran, membuat rumah tahanan, kantor pos, mengatur sistem penggajian, tidka memberi bagian zakat kepada muallaf, dan tidak membagi-bagikan tanah yang ditaklukan kepada prajurit yang menaklukannya.

Dengan menetapkan persyaratan yang ketat, Imam al-Ghazali , sebagaimana dikutip oleh jalaluddin Abdurrahman ${ }^{2}$ menyebutkan bahwa Mashlahah Al-Mursalah hendaklah mashlahat yang disepakati oleh orang-orang Islam tentang keberadaannya dan terbukti dipraktikan dalam kehidupan mereka.

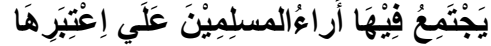

Masalahat tersebut hendaklah disepakati (tidak ada pertentangan) atas keberadaannya di kalangan umat Islam.

${ }^{1}$ Mashlaha mu'tabarah: maslahat yang ditetapkan oleh syara', mashlahah al-mulghah: mashlahah yang dibatalkan oleh (tidak dibenarkan oleh syara'); dan ketiga, maslahah al mursalah: mashlah yang tidak ada dalil terntentu yang membenarkan atau membatalkannya. Lihat dalam buku KH. Ahmad Munif Suratmaputra. Filsafat Hukum Islam al Ghazali; Mashlahah Mursalah \& Relevansinya dengan Pembaruan Hukum Islam. Jakarta: Pustaka Firdaus, 2002). Hal.

2 Jalaluddin Abd. Rahman, Al-Masalih al-Mursalah wa Makanatuha fi al-Tasyri', (Mesir: Matba'ah al-Sa'adah, 1983), Cet. I, hlm 51 
Tentu saja, pandangan Al-ghazali ini mengacu kepada maslahat yang memang telah dianut oleh masyarakat Islam dan disepakati sebagai sesuatu yang mendatangkan manfaat serta dapat pula mencegah terjadinya kemudaratan.

Perumusan Imam al-Ghazali dalam menggunakan mashlahat al mursalah yaitu, Di dalam kitab Syifa' al Ghalil ( شفاء الغليل) al-Ghazali mendefiniskan mashlahat sebagai berikut:

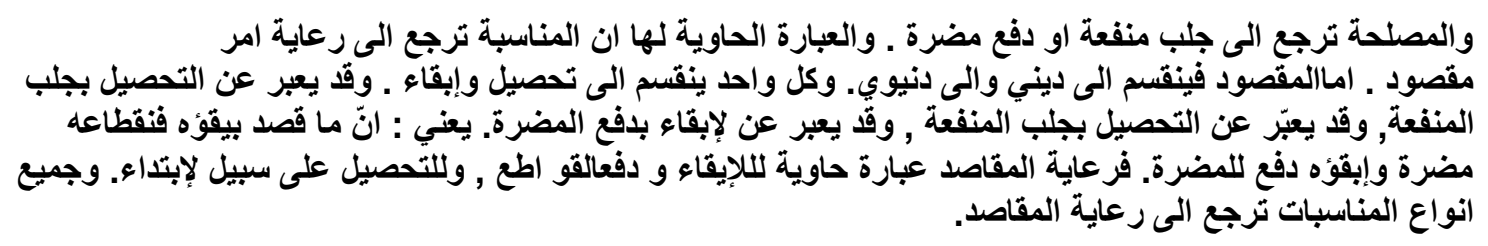

"Maslahat itu kembali kepada menarik manfaat dan menolak mudarat. Ungkapan yang madai tentang mashlahat ini ialah bahwa munasabah (kemaslahatan yang relevan) itu kembali kepada memelihara hal-hal yang dimaksud (oleh agama, hukum Islam). Maksud atau tujuan yang ingin diraih itu ada yang bersifat duniawi. Masing-masing dari keduanya ada yang untuk memperoleh dan ada yang untuk melestarikan. Untuk memperoleh sering diungkapkan dengan menarik manfaat dan untuk melestarikan disebut dengan menolak mudarat. Artinya, kemaslahatan yang dimaksudkan untuk dilestarikan itu apabila lepas/terputus maka timbullah mudarat. Memelihara maqasid (maqasid asy-syari'ah) adalah suatu ungkapan yang mencakup upaya untuk melestarikan kemaslahatan, menolak hambatan-hambatan, dan upanya memperolehnya sebagai langkah awal. Semua macam munasabah (kemashlahatan) adalah dimaksudkan untuk memelihara maqasid (maqasid asy-syariah). ${ }^{3}$

Upaya meraih manfaat atau menolak ke-mudharat-an yang semata-mata demi kepentingan duniawi manusia, tanpa mempertimbangkan kesesuaiannya dengan tujuan syara', apalagi bertentangan dengannya, tidak dapat disebut al mashlahah tetapi إقامة المصالحح وازالة|لمفاسد sebaliknya merupakan mafsadah

Sistem dalam bernegara haruslah disesuaikan dengan kemashlahatan masyarakat secara umum (tujuan umum) namun berdiri di atas mabadi rabbaniyah (prinsip-prinsip ketuhanan). Bahwa negara dibangun atas kebutuhan masyarakat dan untuk memberikan ketertiban dan ketenangan kepada masyarakat secara kolektif maka perwujudan tujuan bersama adalah yang menjadi faktor utama pembentukan sebuah negara. Dan undang-undang yang dibuat dalam suatu negara harus lah berdasarkan kebutuhan rakyat. Hal ini agar tidak terjadinya mafsadat yang lebih besar atau dapat diartikan sebagai mengoptimalkan mashlahah dan meminimalisir kerusakan-kerusakan yang terjadi seperti dalam kaidah تعظيم المصالح وتصغير المفاسد Namun perinsip kenegaraan tersebut tidak boleh dilepaskan oleh mabadi rabbaniyah (prinsip-prinsip ketuhanan) sebagai guidance terhadap jiwa bernegara. Hal ini diperlukan agar terpelihara tujuan dari mashlahah.

${ }^{3}$ K.H. Ahmad Munif Suratmaputra. Filsafat Hukum Islam al Ghazali; Maslahah Mursalah \& Relevansinya dengan Pembaruan Hukum Islam. Jakarta: Pustaka Firdaus, 2002. 
DOI: https://doi.org/10.55252/annawawi.v1i1.6

\section{Interdependensi Al Ghazali}

Apabila ditelusuri di dalam kitab al-Ihya 'Ulumuddin karyanya sangat fenomenal. Al Ghazali mengupas soal tujuan hidup manusia sebagai dasar untuk menetapkan "tujuan negara". Manusia yang bercita-cita bahagia itu, yang menciptakan negara karena satu sama lain saling membutuhkan, maka kebahagiaan itu dijadikan mereka bersama-sama menjadi "tujuan negara” pula. Al Ghazali di dalam kitab tersebut juga menyebutkan tentang asal mula timulnya negara adalah berawal dari manusia itu sebagai makhluk sosial ${ }^{4}$. Teori berdirinya negara menurut Imam al Ghazali tersebut dikenal sebagai teori "interdependensi" ${ }^{5}$. Teori itu mengandung inti bahwa manusia sebagai makhluk sosial bukan hanya bermasyarakat, dan bukan sekedar adanya kontrak masyarakat. Tetapi manusia itu adalah saling bergantung satu sama lain. Secara tegas beliau mengatakan bahwa yang mendorong manusia itu hidup bermasyarakat, ialah kebutuhan hidupnya yang harus setiap saat dan setiap hari diusahakannya. Dan karena kebutuhan itu dia bukan saja bermasyarakat namun saling bergantung satu sama lain.

Disini lah prinsip kedaulatan rakyat terbangun, untuk memenuhi kebutuhan tersebut maka diperlukan negara yang membutuhkan seorang pemimpin dalam mengatur tatanan kemasyarakatan yang ada.

Martabatu tsalatsah merupakan tingkatan dalam prinsip mashlahat al mursalah, yang terdiri dharuratiyat (primer), hajiyat (sekunder) dan tahsiniyyat (tersier). Dalam Kitab al Mustashfa al Ghazali membagi mashlahat dipandang dari segi kekuatan subtansinya. Ia menyatakan:

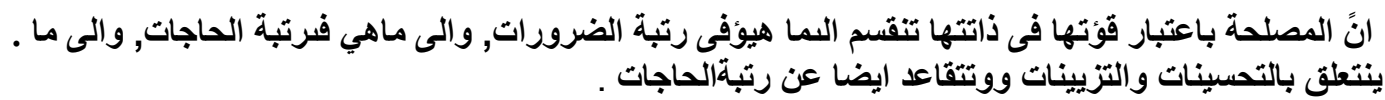

"Mashlahat dilihat dari segi kekuatan subtansinya ada yang berada pada tingkatan dharurat (kebutuhan primer), ada yang berada pada tingkatan hajat (kebutuhan sekunder), dan ada pula yang berada pada posisi tahsinat dan tazyinat (pelengkap-penyempurna), yang tingkatannya berada di bawah hajat." 6

4Teori Interdependensi Imam al Ghazali bahwa manusia tidak dapat hidup sendirian, yang disebabkan oleh dua factor: pertama, kebutuhan akan keturunaan demi kelansungan hidup umat manusia. Hal itu hanya mungkin melalui pergaulan antara laki-laki dan perempuan serta keluarga; dan kedua, saling membantu dalam penyedaiaan bahan makanan, pakaian dan pendidikan anak. Pergaulan pastik akan berakibat lahirnya anak, dan tidak mungkin seseorang secara sendirian menjaga anak sekaligus mencukupi kebutuhan hidup yang lain. Manusia seorang diri tidak akan mampu mengerjakan sawah atau ladangny dengan sempurna. Dia memerlukan alat-alat pertanian, yang untuk pengadaannya diperlukan pandai bersi dan tukang kayu. Untuk penyediaan makanan dibutuhkan penggilingan gandum dan pembuat roti. Untuk pengadaan pakain diperlukan tukang tenun dan penjahit. Manusa, berbeda dari kebanyakan binatang, tidak sanggup di dalam terbut. Demi kesehatan dan keamannya dia memerlukan tempat tinggal atau rumah yang kokoh dan kuat untuk melindunginya dari udara panas, udara dingin, hujan, dan gangguan orang-orang yang jahat atau yang pencuri dan serangan dari luar. Untuk itu semua diperlukan kerjasama dan saling membantu antar sesama manusia, antara laind engan membangun pagar-pagar tinggi disekeliling pusat perumahan, dan disanalah lahir negara karena dorongan kebutuhan bersama. Lihat ddalam buku H. Munawir Sjadzali. Islam dan Tata Negara; ajaran; sejarah dan pemikiran (Jakarta: Universitas Indonesia Press, 2018). Hal 72 .

${ }^{5}$ Teori Interdependensi adalah istilah yang dikemukakan oleh HK. Sherwani di dalam bukunya "H.K.Sherwani. Muslim Political Thought and Administration (Lahore: Kazi Pubns Inc, 1945).

6 K.H. Ahmad Munif Suratmaputra. Filsafat Hukum Islam al-Ghazali; Maslahah Mursalah \& Relevansinya dengan Pembaruan Hukum Islam. Jakarta: Pustaka Firdaus, 2002) 
Bernegara berada tingkatan hajat dan mendekati kepada tingkatan dharuriyyah (kebutuhan primer). Hal ini dapat dilihat bagaimana al Ghazali menceritakan terbentuknya negara di dalam kitabnya al Ihya 'Ulumuddin bahwa negara terbentuk dari adanya kebutuhan-kebutuhan pokok manusia dalam hal pangan, keamanan dan keturunan. HK Sherwani menyebut teori berdirinya negara yang dikemukakan oleh al Ghazali sebagai teori interdependensi (saling bergantung). Di dalam teori tersebut juga menunjukan bahwa negara merupakan sarana dalam mencapai tujuan bersama.

Dalam mashlahat al mursalat negara memiliki fungsi utama untuk melayani masyarakat, atau dalam kata lain negara dalam mewujudkan kemashlahatan tersebut maka negara harus mampu untuk memberikan pelayanan kepada publik (khidmat ijtima'i). Sebagaimana tertera dalam kaidah fiqh sebagai pemegang amanah harus selalu berorientasi pada kemaslahatan umum (tasharruf al-imam 'ala al-ra 'iyyah manuth bilmaslahah).

Al-Ghazali di dalam kitabnya al-Iqtishadu Fil 'Itiqad kedua mukaddimah yang merupakan dalil-dalil bagi harus diadakannya kepala negara adalah: pertama, sesungguhnya keberesan agama tidaklah tercapai kalau dunianya tidak beres, sedang keberesan dunia tergantung kepada adanya kepada negara yang ditaati. Kedua, ketentraman dunia dan keselamatan jiwa dan harta, hanyalah dapat diatur dengan adanya kepala negara yang ditaati. Inilah sebabnya, agama dan negara adalah dua saudara kembar yang tidak terpisahkan. Atau dikatakan: agama adalah tiang, dan negara (kepalanya) adalah penjaga. Sesuatu yang tidak ada tiang tentu akan tubuh, sebagai halnya sesuatu yang tidak ada penjaga pastilah tersia-sia.

Oleh karenanya konsep negara yang dirumuskan oleh al-Ghazali adalah negara yang berkonsep theo-democracy (demokrasi yang berdasarkan ketuhanan) dan bukan berbentuk theocracy (Negara Tuhan).

\section{Konsep Kenegaraan \\ Al Ghazali}

Imam al Ghazali berpendapat bahwasanya negara terbentuk karena adanya faktor sosial (kemasyarakatan) dan kekuasaan khalifah atau Imam bukan diturunkan dari Tuhan, namun berdasarkan kekuasaan yang diberikan oleh rakyat. Al-Ghazali juga berpendapat bahwa negara (pemerintahan) merupakan suatu keharusan. Pemerintah wajib ditegakan karena ia berfungsi memelihara dunia ini dari kehancuran dan kerusakan. Ini pula merupakan institusi yang diperlukan oleh kaum muslim melalui ijma' masyarakat, setelah kematian nabi Muhammad saw ketika pemeliharaan tatanan agama dan politik mengharuskan umat untuk memiliki seorang khalifah (kepala negara).

Di masa Imam al Ghazali, praktik politik dan pada pemerintahan Bani Abbasiyyah pengangkatan khalifah dilakukan melalui penunjukan oleh khalifah sebelumnya, secara turun temurun berdasarkan ikatan keluarga. Namun, yang bertentangan dengan itu adalah pemikiran al Ghazali yang ketia kitabnya membuat konsep kenegaraan yang justru bersifat demokratis. Bahwa kepemimpinan seorang khalifah yang dibuat dalam suatu negara haruslah sesuai dengan yang menjadi tujuan bersama. Tujuan dari seluruh rakyat secara kolektif dan adanya pengawasan yang dilakukan oleh majlis terhadap kekuasaan pemerintah tersebut agar kekuasaannya yang dilakukan tidak kelaur dari tujuan bersama. ${ }^{7}$

Al Ghazali tidak menentang secara keras praktik pemerintahan pada zamannya karena apabila hal tersebut dilakukan tidak akan membawa mashlahat kepada rakyat seara keseluruhan namun akan merugikan negara dan seluruh rakyat. Oleh karena itu al-Ghazali menganjurkan dibatasinya kekuasaan seorang raja dan supaya badan-badan yang menjalankan kekuasaan itu haruslah berbentuk dewan atau majlis yang terdiri

7 Ibid. Hal 72. 
dari para ahli yang jujur. Dalam kitab Tibrul Masbuq fi Nashihati al Muluk menunjukkan bahwasanya al Ghazali tidak menyetujui akan sifat "pribadi" yang memegang kekuasaan, tetapi haruslah setiap lembaga di pegang oleh suatu dewan (majlis) yang semua anggotanya bekerja secara kolektif.

Al-Ghazali dalam ketiga kitabnya berpendapat bahwa agama dan Negara berhubungan erat seperti saudara kembar yang lahir dari satu Ibu (tawamun), dan hubungan simbiotik ini -barangkali merupakan jalan tengah antara paradigma "bersatunya agama dengan negara" (integrated paradigm) sebagaimana yang dianut kaum syi'ah dan fundamentalis dan paradigm sekuler (secular paradigm) yang memisahkan secara tajam antara agama dan negara.

Menurut H. Zaenal Abidin dalam bukunya "konsep negara bermoral menurut Imam al Ghazali", bahwa negara yang diusungkan oleh Imam al Ghazali adalah negara akhlak yaitu negara kerakyatan, dimana kekuasaan tertinggi berada di tangan rakyat dan seluruh politik negara dan pekerjaan pemerintahan diliputi oleh semangat akhlak dan jiwa agama."

Demokrasi menurut al Ghazali berbeda dengan konsep demokrasi sekuler. Teori demokrasi menurut al Ghazali adalah dari rakyat, untuk rakyat, karena Tuhan (from the people, to the people, by God). Sedangkan demokrasi modern yang kosong dari suara wahyu dari Tuhan, yang berbunyi: "dari rakyat, untuk rakyat, oleh rakyat (from the people, to the people, by the people)." 8

Demokrasi Islam menurut al Ghazali adalah meletakan hukum Tuhan di atas dan diluar dari kebebasan. Ini lah artinya semboyan yang dikemukakan oleh al-Ghazali di atas: dari rakyat, untuk rakyat, oleh (karena) Tuhan.

Negara Islam tidak bersifat teokratik. Islam tidak pernah mengajarkan dibentuknya negara teokratik dalam pengetian seperti digunakan dalam konteks sejarah politik barat yang mengalami pertentangan hebat antara negara dan gereja. Menurut Islam, kehidupan merupakan kesatuan yang tidak dapat dipisahkan antara kehidupan batin (spiritual) dan kehidupan lahir (mundane) sebagaimana diungkapkan oleh al Ghazali di dalam kitab Ihya 'Ulumuddin bahwa:

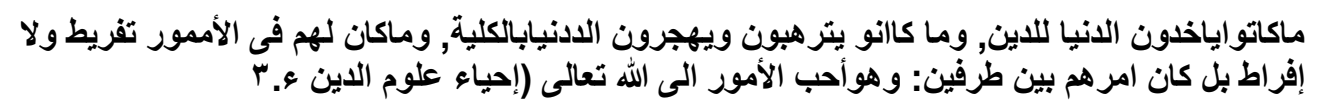

Al Ghazali dalam konsep Negara teodemokrasi menggunakan mashlahah al mursalah sebagai dasar hukum dalam rangka membangun Negara yang berkedaulatan rakyat dengan menggunakan prinsip-prinsip ketuhanan (mabadi rabbaniyah). Konsep teodemokrasi, merupakan suatu konsep negara moderat (tawashutiyyan), adalah suatu konsep Negara, yang tidak berbentuk Negara Tuhan atau Negara Sekuler tapi berada di tengah antara dua model Negara tersebut yaitu Negara yang tetap berada dalam koridor etiket serta prinsip-prinsip ketuhanan namun pada saat bersamaan memberikan soverignitas dalam teknikal kehidupan bernegara kepada suatu bangsa.

\section{KESIMPULAN}

Berdasarkan analisis di atas diperoleh kesimpulan bahwa Imam al Ghazali merumuskan Konsep kenegaraan yang tawasuthiyyah (moderate)yang disebut konsep Negara theodemokrasi, melalui pendekatan ushul fiqh yaitu mashlahahah al- mursalah, sebagaimana diketahui bahwa masalah kenegaraan adalah merupakan ruang lingkup fiqih mumalah. Konsep Negara teodemocracy adalah dimana kekuasaan tertinggi berada di tangan rakyat dan seluruh politik negara dan pekerjaan pemerintahan diliputi

8 H. Zaenal Abidin Ahmad, Konsepsi Negara Bermoral Menurut Imam Al-Ghazali (Jakarta: Bulan Bintang, 1975) 
oleh semangat akhlak dan jiwa agama. Dimana Demokrasi menurut al Ghazali berbeda dengan konsep demokrasi sekuler. mashlahah al mursalah sebagai dasar hukum dalam rangka membangun Negara yang berkedaulatan rakyat dengan bersandarkan kepada prinsip-prinsip ketuhanan (mabadi rabbaniyah).

Teori berdirinya negara menurut Imam al Ghazali tersebut dikenal sebagai teori "interdependensi". Teori itu mengandung inti bahwa manusia sebagai makhluk sosial bukan hanya bermasyarakat, dan bukan sekedar adanya kontrak masyarakat. Tetapi manusia itu adalah saling bergantung satu sama lain. Disini lah prinsip kedaulatan rakyat terbangun, untuk memenuhi kebutuhan tersebut maka diperlukan negara yang membutuhkan seorang pemimpin dalam mengatur tatanan kemasyarakatan yang ada. Di dalam bukunya Imam al-ghzalai menuliskan bahwa agama dan negara adalah dua saudara kembar yang tidak terpisahkan, "agama adalah tiang, dan negara (kepalanya) adalah penjaga." Sesuatu yang tidak ada tiang tentu akan rubuh, sebagai halnya sesuatu yang tidak ada penjaga pastilah tersia-sia.

Oleh karenanya konsep negara yang dirumuskan oleh al-Ghazali adalah negara yang berkonsep theo-democracy (demokrasi yang berdasarkan ketuhanan) dan bukan berbentuk theocracy (Negara Tuhan).

\section{DAFTAR PUSTAKA}

Abu Hamid Al-Ghazali. At-Tibr al-Masbuq fi nashihati al Muluk (Beirut: Darul Kutub al-'alamiyyah, 1988)

Jalaluddin Abd. Rahman, Al-Masalih al-Mursalah wa Makanatuha fi al-Tasyri’, (Mesir: Matba'ah al-Sa'adah, 1983),

Radjab, Dasril. Hukum Tata Negara Indonesia (Jakarta: PT. Tineka Cipta, 2005)

Nur Mufid \& Nur Fuas. Al-Ahkamus Sulthaniyyah Al-Mawardi (Surabaya: Pustaka Progresssif, 2000)

K.H. Ahmad Munif Suratmaputra. Filsafat Hukum Islam al-Ghazali; Maslahah Mursalah \& Relevansinya dengan Pembaruan Hukum Islam. Jakarta: Pustaka Firdaus, 2002)

H. Munawir Sjadzali. Islam dan Tata Negara; ajaran, sejarah dan pemikiran (Jakarta: Universitas Indonesia Press, 2008)

Soehino. Ilmu Negara (Yogyakarta: Liberty, 1998)

Abu Hamid al-Ghazali. Al-'Itiqad fi al-`Itishad. Valume I. (Beirut: Darul Kutub al-'alamiyyah, 1998)

Abu Hamid al-Ghazali. Al-'Itiqad fi al-'Itishad. Valume II. (Beirut: Darul Kutub al-'alamiyyah, 1998)

H. Zaenal Abidin Ahmad, Konsepsi Negara Bermoral Menurut Imam al-Ghazali (Jakarta: Bulan Bintang, 1975)

H.K. Sherwani. Muslim Political Thought and Administration (Lohore: Kazi Pubns Inc, 1945)

Jazuni. Legislasi Hukum Islam di Indonesia (Bandung: Citra Aditya Bakti, 2005)

Deliar Noer. Mohammad Hatta Hati Nurani Bangsa. (Jakarta: Kompas Media Nusantra, 2012)

Ali Yafie, "antara Ketentuan dan Kenyataan?" dalam Iqbal Abdurrauf Saimima (ed), Polemik Reaktualisasi Ajaran Islam, cetakan pertama, (Jakarta: Pustaka Panjimas, 1988) 